\title{
Notas sobre el derecho humano a la familia como derecho motor para el ejercicio de otros derechos humanos*
}

Approach to Human Right to the Family, as an Essential Right for the Exercise of Other Human Rights

Enrique Uribe-Arzate ${ }^{\mathrm{a}}$

Universidad Autónoma del Estado de México, México

euribea@uaemex.mx

ORCID: http://orcid.org/0000-0003-2381-232X

Martha Guadalupe Bustamante-Medrano

Universidad Autónoma del Estado de México, México

ORCID: http://orcid.org/0000-0001-5564-2076
DOI: https://doi.org/10.11144/Javeriana.vj138.ndhf Redalyc: http://www.redalyc.org/articulo.oa $?$ id=82559799011

Fecha de recepción: 02 Septiembre 2016 Fecha de aprobación: 14 Agosto 2018 Fecha de publicación: 30 Mayo 2019

\section{Resumen:}

Actualmente, los derechos humanos enfrentan un difícil proceso de aproximación a su disfrute efectivo. En la doctrina y en la legislación, hay un notable desarrollo declarativo sobre los derechos humanos. Sin embargo, el gran problema tiene lugar cuando las personas intentan ejercerlos y disfrutarlos, porque no hay condiciones óptimas para esto. Algunos de los derechos humanos "más esenciales" pueden volverse realidad, si los ubicamos en el contexto del derecho humano a la familia, que como nuevo derecho humano, tiene la capacidad para servir como derecho motor para el ejercicio de otros derechos humanos que no tienen mejor escenario para su disfrute que la familia.

Palabras clave: Derechos humanos, familia, vulnerabilidad, políticas públicas, garantías.

\section{Abstract:}

Nowadays, human rights face a difficult process towards their effectiveness in people's ordinary lives. There is no denying that human rights theory and doctrine have experienced some remarkable progress. The problem, nonetheless, is of a practical nature, when citizens try to exercise them. This is a problem because the optimal conditions are lacking. Some of the "most essential" human rights can become a reality, if we place them in the context of the human right to the family, which, as a new human right, has the capacity to be useful as an essential right for the exercise of other human rights that they have not better context for their warranty than the family.

Keywords: Human rights, family, vulnerability, policies, warranties.

\section{Nota introductoria}

El presente estudio se encuadra en el análisis de un derecho humano apenas germinal que, en nuestra opinión, puede potenciar el disfrute de otros derechos humanos; se trata del derecho humano "a la familia" que —en la tesis aquí desarrollada - puede servir como derecho motor de otros derechos esenciales. Es necesario advertir que, sin ser el objeto central de nuestro estudio, el matrimonio y las modalidades de este se imbrican con la familia y por eso, es pertinente hacer un breve tratamiento de estas cuestiones.

En México, en particular, ha resurgido el debate acerca de la configuración y permisión jurídica de los matrimonios entre personas del mismo sexo; a la par, la discusión se ha extendido al concepto de familia, a los fines de esta y a la posibilidad de las uniones de personas del mismo sexo de adoptar a un niño. Las consideraciones y los argumentos vertidos por los partidarios de una y otra postura han polarizado a la sociedad mexicana y es difícil adelantar una salida que concilie ambas posturas. Por si fuera poco, los

Notas de autor:

$$
\text { a Autor de correspondencia. Correo electrónico: euribea@uaemex.mx }
$$


pronunciamientos políticos y jurídicos sobre la cuestión tampoco han faltado y, por ello, el asunto se ha vuelto ríspido y hasta irracional.

Uno de los alegatos principales de quienes sostienen la constitucionalidad de la unión entre personas del mismo sexo, está centrado en la idea de igualdad y no discriminación que, según ellos, se trastoca al no permitir este tipo de uniones. Por su parte, quienes sostienen lo contrario aducen argumentos de orden natural y religioso, como que "no es natural" que dos hombres formen un matrimonio y se les permita adoptar y educar a un menor. El argumento esgrimido en contra sostiene que lo "no natural" inunda la vida de los seres humanos, v. gr., las prótesis o los medicamentos, y que todo esto ha servido a la humanidad. Según nuestro parecer, el debate no se ha focalizado en la parte central; por un lado, ni la igualdad ni la no discriminación pueden asentarse en la idea de libertad sin reglas, ni la idea de lo natural o biológico es sólido soporte para restringir el libre albedrío.

Solo para ubicar nuestro objeto de investigación adecuadamente, podemos afirmar que el punto álgido de esta controversia se sitúa en la constitucionalidad de las instituciones que sirven para la vida humana plena. Lejos de cualquier asomo de homofobia, consideramos que las uniones de personas del mismo sexo son un asunto de la incumbencia absoluta de quienes deciden esto. Cuestionable o no, el sentido en que la libertad puede ser ejercida (incluso abusada), lo cierto es que la temática que nos ocupa desborda el ámbito de lo jurídico y de lo constitucional, para insertarse en el campo de la moral y del respeto a los principios señeros de la religión y de manera destacada, pero no exclusiva, a los preceptos de la iglesia católica.

Más allá de estas reglas y preceptos, aquí nos interesa tratar lo concerniente a la familia que, desde luego, pertenece a otro nivel de discusión, aun cuando su basa derive de la unión de dos personas; si estas personas son homosexuales, bisexuales, heterosexuales, etc., esto es un asunto que - nos parece- toca tangencialmente la cuestión que de manera central ocupará nuestro análisis. La parte nodal está en la existencia de la familia como núcleo y contexto de cualquier posibilidad de desarrollo pleno. Sobre esto, los alegatos que sostienen que es preferible que los menores estén en un hogar de homosexuales que en un albergue, o que no está científicamente comprobado que el niño adoptado por homosexuales esté destinado a ser él mismo homosexual, poco abonan a la cuestión que nos interesa abordar.

Por eso, para nuestro estudio, dejamos de lado este debate, pues no sirve para delinear el sentido y alcances del derecho humano y fundamental a vivir en familia. Nos parece suficiente con decir que todo ser humano tiene ese derecho; lo tienen los ancianos, las mujeres, los miserables de la calle, los migrantes, los homosexuales, los militares, los refugiados... ¿Carecen de este derecho los hijos de las prostitutas o los hijos de narcotraficantes? Creemos que no; en todo caso, no es correcto criminalizar a los hijos, y así como no se puede etiquetar a los hijos de prostitutas y delincuentes, tampoco es correcto estigmatizar al menor que vive en un hogar distinto al constituido por las familias nucleares típicas. Ahora bien, no sobra puntualizar que un escenario es la vida de un menor en una familia nuclear, monoparental o ensamblada y otro contexto distinto es el caso de los niños que ex profeso se pretende adoptar por dos personas del mismo sexo; desde luego, no nos referimos al caso de la madre soltera o al de las hermanas divorciadas que viven bajo el mismo techo con sus respectivos hijos y sobrinos; este es un hecho que acontece de manera distinta al propósito expreso de dos homosexuales de adoptar a un niño. Como derecho universalmente reconocido, el derecho a vivir en una familia es irreductible. Desde luego, las condiciones óptimas para que la vida en familia potencie la vida humana, no se dan en todos estos casos; es decir, no siempre los niños que viven en familias tradicionales, gozan de las mejores condiciones y tampoco los niños que viven en familias distintas están condenados a sufrir menoscabo en sus derechos humanos. La perspectiva científica sobre esto tiene todavía mucho qué decir.

En lo que toca a nuestro estudio, la tesis central sostiene que el derecho humano a la familia es un derecho mayor, un derecho potencia que sirve de plataforma para el desarrollo y disfrute de otros derechos humanos. En este orden de ideas, de entrada, podemos afirmar que, aunque todos los derechos humanos tienen similar naturaleza, hay algunos de estos que adquieren mayor relevancia en el contexto de su potenciación; por eso, hemos identificado el "derecho humano a la familia" como un derecho matriz y a la vez como un derecho 
motor; es un derecho matriz porque es un derecho central; es motor porque sirve como impulso para otros derechos. Sin ánimo de contribuir a la polarización señalada al principio, nos parece que más allá de la libertad y la igualdad, "el derecho a la familia" es un derecho humano, universal, progresivo y en expansión que debe alcanzarnos a todos, independientemente de las circunstancias personales de cada cual. A fin de cuentas, la familia es, y no ha dejado de ser, el cobijo y ambiente natural para el desarrollo humano; su ausencia o debilidad hacen difícil, cuando no nugatoria, la vida humana ${ }^{1}$. Como advertencia, vale decir que no se trata de un estudio de antropología, etnografía o de corte sociológico, sino estrictamente jurídico (por más que en él haya incidencias transdisciplinarias que intenta eslabonar el concepto familia con los derechos humanos que se conectan o confluyen en esta institución humana.

La ruta a seguir inicia con un breve recorrido conceptual para ubicar adecuadamente nuestro objeto de estudio; continuamos con la delimitación teórica necesaria para apuntalar el desarrollo de la cuestión, en que destaca el ejercicio heurístico encaminado a generar una nueva orientación de los derechos humanos que se vinculan con el ser de la familia; sigue la revisión del estado de la cuestión en materia de derecho positivo en los marcos nacional e internacional; y desemboca en el análisis de la proyección pragmática del derecho en estudio; finalmente, concluimos con algunos trazos propositivos que esperamos sean útiles para ulteriores desarrollos sobre este tópico.

\section{La familia: concepto, vulnerabilidad y límites}

Sobre el concepto familia hay incontables acercamientos. Bástenos para este trabajo, con citar dos que, a su vez, delinean dos concepciones ciertamente opuestas. Una señala que: "la familia como santuario de la vida es el lugar donde madura la vocación humana y cristiana y es el elemento unificador de la sociedad” ${ }^{2}$. Otra nos dice que: "La familia es un grupo social, organizado como un sistema abierto, constituido por un número variable de miembros que en la mayoría de los casos conviven en un mismo lugar, vinculados por lazos ya sean consanguíneos, legales y/o de afinidad" ${ }^{3}$. En el primer caso que asume una orientación religiosa, la liga con el concepto de matrimonio es evidente y a la vez decisiva. En el segundo, se advierte una visión muy abierta y, por lo mismo, poco precisa. Los conceptos antes referidos solamente tratan de llamar la atención sobre la disputa que tiene lugar en el intento por aprehender adecuadamente el tema que nos ocupa.

La familia - o mejor dicho, los distintos tipos de familias - es un asunto de gran complejidad. Por eso, como dicen CECILIA GROSMAN e IRENE MARTÍNEZ-ALCORTA: "El reconocimiento de tipos familiares diversos y su expresión en los discursos del saber, al darles legitimidad y desnudar mitos, actúa en el dominio de las conductas, valores y representaciones sociales. Representa, igualmente, la afirmación del principio democrático que exige el respeto por las diferencias" ${ }^{4}$. Esta manifestación evidencia la poca claridad o incluso la ligereza con que es posible calificar de manera genérica cualquier tipo de unión y darle el mismo nombre; indiscutiblemente, reconocer tipos familiares distintos y respetar las diferencias es un ejercicio democrático vital para las sociedades. Nos parece que las afirmaciones como la aquí citada, deben ser más mesuradas, pues de lo contrario, la consecuencia lógica será incluir cualquier tipo de relación como fundamento de la familia ${ }^{5}$. Es pertinente hacer un alto aquí, para expresar claramente nuestro pensamiento en relación con el tema abordado; con independencia de cuál sea nuestra preferencia sexual o nuestra manera de concebir al matrimonio, nos parece irrefutable la necesidad de realizar investigación y aproximaciones científicas que aporten y contribuyan a la atención de estas cuestiones que a todos nos interesan. Poco podemos contribuir a la reflexión si nos lastra la descalificación: la de la iglesia a la que se ha calificado de cerrazón; la del movimiento LGBTTTI [lesbianas, gays, bisexuales, transgéneros, travestis, transexuales e intersexuales] a quienes se tilda de enfermos. A fin de cuentas, no son ajenos a nosotros, no son extraños; son seres humanos como nosotros ${ }^{6}$.

Como podemos colegir de lo antes tratado, la familia —o los distintos tipos de familia - es un tema que no ha agotado sus perspectivas teóricas. Por nuestra parte y para este trabajo, cualquiera de las definiciones 
aportadas por los especialistas es útil como referencia a un derecho humano irreductible y vital. Ahora bien, el concepto de familia y su desarrollo como derecho humano se vinculan con otra idea matriz, referida a la vulnerabilidad que esta institución afronta. Por ello, además de la adecuada concepción del objeto de estudio, es indispensable superar los problemas que limitan el acceso a su disfrute pleno. En este punto, es pertinente señalar que nuestro objeto de investigación tiene una doble vertiente que origina dos grandes rutas para su tratamiento: por un lado, el derecho humano a la familia que se configura como un derecho humano reciente de corte individual y, por otra parte, el derecho humano de la familia que hace evidente la configuración de un nuevo derecho grupal. Nuestras disquisiciones abordarán solamente el primer derecho aquí destacado.

Desde luego, ambas orientaciones de este derecho favorecen el ejercicio y tenencia de otros derechos y requieren medios de protección adecuados, viables y accesibles a los habitantes. Como este punto lo trataremos más adelante, por ahora basta con remarcar la importancia de esta concepción teórica y la necesidad de superar las evidentes limitaciones y riesgos — visibles desde la vulnerabilidad — que afronta la familia.

Al respecto, el concepto de vulnerabilidad es multívoco y ha sido utilizado en diversos campos del conocimiento, como la sociología, la economía ${ }^{7}$ o el derecho. La certeza de que los seres humanos están en riesgo y la posibilidad de sufrir menoscabo en cualquier aspecto de su vida, ha servido para desarrollar esta idea. Ser vulnerable coincide con la posibilidad de sufrir menoscabo. Así: "Vulnerability initially should be understood as arising from our embodiment, which carries with it the ever-present possibility of harm, injury, and misfortune from mildly adverse to catastrophically devastating events, whether accidental, intentional, or otherwise" ${ }^{8}$. Más allá de nuestra naturaleza vulnerable, el concepto de vulnerabilidad aplicable al presente estudio debe ser comprendido en un sentido diferente, pues el hilo conductor no se agota en la mera exposición de las personas a riesgos, sino antes bien, a la proyección fáctica de esos riesgos que, una vez actualizados, hacen vivenciales las condiciones de rezago y/o desventaja de las personas.

De este modo, la vulnerabilidad no se constriñe a la posibilidad (potentia) que tienen los seres humanos de ser violentados en sus derechos, sino que se proyecta además al momento vivencial en que tal vulneración acontece (acto); es decir, la vulnerabilidad - como riesgo o como posibilidad- adquiere otra proyección cuando el riesgo se materializa, porque entonces la naturaleza humana muestra su concreta fragilidad; esa que en general compartimos los seres humanos y que en ciertas condiciones y para determinadas categorías, identifica grupos concretos de personas. Un ejemplo puede servir para expresar mejor esto: el derecho a la vida 9 nos asiste a todos los seres humanos; pero también, de manera indistinta, los seres humanos enfrentamos cotidianamente el riesgo de perder este bien invaluable; por ello, el solo riesgo nos hace iguales y nos identifica como vulnerables potenciales; así, cuando alguna persona es privada de la vida, la actualización de este acontecimiento la traslada de la condición de vulnerable in potentia a vulnerable in acto. En el primer caso general, la vulnerabilidad nos abarca a todos y por ello, somos igualmente vulnerables; en el segundo supuesto, el vulnerable se convierte en víctima y en esa condición, la vulnerabilidad implica la victimización que es típica en el caso de violación a derechos fundamentales.

La vulnerabilidad a que nos referimos en estos términos, se da lo mismo en personas particulares que en grupos sociales o segmentos de la sociedad. Vulnerables son los invidentes, los niños y los ancianos; los migrantes y los desplazados por la guerra, los marginados y los analfabetos...; vulnerable es la familia. La vulnerabilidad alcanza amplios segmentos de la sociedad y prácticamente no distingue países, regiones o latitudes. En este sentido, la vulnerabilidad implica además el tema de victimización ${ }^{10}$, pues, en este caso, la vulnerabilidad rebasa la condición de víctima que es posible describir desde el derecho penal. En este campo, la víctima es quien sufre un daño producto de algún delito. En el plano que nos ocupa, la víctima puede serlo incluso sin delito; esto se explica a partir de la idea de que el mismo Estado puede ser agente promotor de estos fenómenos, desde el momento mismo en que es omiso en la atención de la problemática de los vulnerables y, 
todavía más, cuando está ausente en el diseño de políticas públicas pertinentes para atender las condiciones de desventaja de grandes sectores de la población ${ }^{11}$.

En este orden de ideas, el impacto de la vulnerabilidad es todavía mayor, pues en los casos concretos en que esto tiene lugar, las condiciones de desventaja y el riesgo de las personas parecen ser un asunto individual, concreto, sin mayor proyección. Empero, cuando la vulnerabilidad se traslada hasta la omisión estatal de las políticas públicas para atender las condiciones de marginación y riesgo ya apuntadas, el asunto es más grave, pues afecta a más personas y el mecanismo de lesión ni siquiera requiere de una agresión directa o personal. Por eso, decimos que la vulnerabilidad que se proyecta hasta la victimización, impone una vulnerabilidad presente, actual; id est, convierte a las personas en vulnerables vulnerados ${ }^{12}$.

En este sentido, la vulnerabilidad in acto adquiere un significado más profundo, debido a la violación constante y permanente a los derechos humanos que prácticamente se da en cualquier lugar. No basta con decir que los seres humanos podemos sufrir algún agravio o menoscabo a la condición de persona o a los derechos personales, patrimoniales o familiares. En nuestra opinión, la sola posibilidad de estar expuestos a estos riesgos nos sitúa como vulnerables en potencia. De otro lado, la materialización de la violación nos convierte de inmediato en vulnerables in acto; esto es, ante alguna violación a nuestros derechos humanos, pasamos de vulnerables en riesgo a vulnerables ya vulnerados.

De acuerdo con este hilo argumental, la familia y los derechos que les asisten a sus integrantes en lo individual y en lo colectivo están expuestos a la vulnerabilidad ya apuntada. La familia es un ente vulnerable y en ciertas condiciones, se sitúa incluso como vulnerable vulnerado. ¿Cómo salvaguardar el derecho elemental de todo ser humano a vivir en familia? Creemos que justamente en su dimensión como derecho humano de nueva generación, el derecho humano a la familia puede ser no solo el anclaje teórico de otros derechos igualmente esenciales, sino también el motor para el desarrollo de esos derechos vitales que fuera de la familia son de muy difícil concreción; pensemos en el derecho a la alimentación (ningún albergue lo puede garantizar; en el derecho a la educación (ninguna escuela — ni siquiera las de tiempo completo- lo puede asegurar; o el derecho a la recreación, a la cultura, al medio ambiente sano; ninguno de estos derechos puede asirse por el individuo — niño, mujer, hombre, anciano, viuda, soltero, homosexual o heterosexual - fuera de la familia. Por eso, la exposición de la familia — y del derecho humano a la familia - a riesgos evidentes debe ser un tema de tratamiento y regulación normativa, a fin de evitar que del concepto de vulnerabilidad (siempre latente, pasemos a la realidad de vulnerable vulnerado que trastoca y lesiona este derecho esencial.

\section{Hacia un nuevo derecho humano}

Hemos dicho que el objeto de nuestro estudio se desdobla en dos vertientes: el derecho humano individual a la familia y el derecho humano grupal de la familia. Podemos definir el primero, objeto de nuestro estudio, como el derecho humano a formar parte de una familiay ser beneficiario de su concreciónpragmática. La segunda expresión se refiere al derecho humano del grupo familiar de disfrute colectivo; se trata de una entidad que una vez integrada, representa un nuevo escenario para el desarrollo del derecho humano colectivo que guarda enormes diferencias con el derecho individual concreto que le da nacimiento. Así, el derecho humano a la familia del niño o del anciano es un derecho que permite su inserción en una familia; y, en este segundo momento - ya integrado el grupo familiar-, el derecho de la familia se configura como un derecho colectivo distinto al de cada uno de los integrantes cuya protección el Estado debe procurar ${ }^{13}$, a la luz de su irreductible compromiso con los derechos y sus garantías ${ }^{14}$.

A partir de esta categoría, podemos argumentar que los derechos inherentes a los seres humanos deben formar parte de la construcción científica que nos ocupa en este trabajo, pues de poco sirve un diseño epistemológico conceptual-descriptivo que nada diga sobre los modos en que es posible la concreción fáctica de la vulneración a derechos humanos y tampoco nada exprese sobre la posibilidad real de dar protección a los 
derechos inherentes a los seres humanos, incluso antes de que estos se conviertan en vulnerables vulnerados. Esta es la natura de los derechos humanos, su textura, su desiderätum. Cualquiera de estos debe ser mirado así para estar en la posibilidad real de su protección, pues la ausencia de garantías hace nugatorio y ficticio cualquier derecho ${ }^{15}$.

Ahora bien, tal vez el principal asunto en este rubro se refiere a las distintas proyecciones de los derechos humanos. Aun cuando todos merecen el mismo tratamiento e idénticas consideraciones, es innegable que algunos derechos conllevan en su natura, una capacidad mayor ${ }^{16}$ para el desarrollo de otros derechos -igualmente relevantes y esenciales, pero limitados en cuanto a su proyección y alcances-. El derecho humano a la familia pertenece a esta categoría, a pesar de que se encuentra en una fase inicial de desarrollo. De la literatura consultada y de los autores que han tratado esta cuestión, no se desprenden las características, reglas y condiciones para la puesta en marcha de un derecho de estas características. JOSÉ CARLOS DE BARTOLOMÉ-CENZANO señala: "Sin embargo, el desarrollo tecnológico —el gran avance experimentado por los medios de comunicación social- ha exigido la configuración de un nuevo derecho con carácter autónomo, el derecho a la intimidad personal y familiar" ${ }^{17}$. Justamente por la vaguedad que lo acompaña, el derecho en estudio hace patente la complejidad de su tratamiento. Por ello, los pronunciamientos contenidos en el presente trabajo dan cuenta de una exploración que apenas opera como búsqueda de las rutas epistemológicas de mayor pertinencia. Se trata del punto de partida de ejercicios intelectuales y de construcción científica que estarán por venir. En seguimiento de estas ideas, la liga entre el derecho a la familia y la vulnerabilidad se desprende de una fórmula bastante elemental:

Derecho humano a la familia + Vulnerabilidad = Derecho bumano conculcado

Desde luego, no puede haber un derecho a la familia pleno, si en las políticas públicas del Estado falta una planeación incluyente que permita el desarrollo de mecanismos, instituciones y procedimientos que den viabilidad al disfrute del citado derecho. La vulneración de este derecho incipiente tiene lugar a través de la violación cotidiana de otros derechos desde su proyección individual. Una vez que se violentan los derechos de corte individual, el sustancial derecho a la familia es prácticamente nugatorio y ni siquiera es posible su configuración.

Esto se puede plantear en términos más generales, diciendo que los derechos de corte individual violentados, como el derecho a la alimentación, el derecho al desarrollo, el derecho a una vida libre de violencia (todos estos derechos de corte y disfrute individual), dan como resultado en la sumatoria, un derecho a la familia fragmentado y de limitada proyección. Luego entonces, es menester señalar que el Estado debe ser el principal agente promotor de los escenarios y las condiciones idóneas para que el derecho a la familia acabe de configurarse y comience su desarrollo efectivo, más allá del discurso que se proyecta sobre derechos más específicos y, por lo tanto, menos demandantes en su construcción científica e incluso en su justificación. De acuerdo con lo que vamos señalando, el itinerario para ligar y explicar esto se puede dar así:

FASE 1. Hay derechos humanos de corte individual concreto:

$V \cdot g r$. Derecho a la alimentación, al nombre, a la nacionalidad, a la educación.

FASE 2. Estos derechos tienen notas distintivas:

Universalidad, indivisibilidad, progresividad, irreductibilidad.

FASE 3. El derecho humano a la familia tiene carácter transversal.

Por sus características, atraviesa la parte esencial de todos los otros derechos inmanentes al ser humano (la vida, el desarrollo, la alimentación, la educación, la protección).

FASE 4. El derecho a la familia actúa como derecho garante, como un derecho motor, como un derecho que potencia los demás derechos esenciales. 


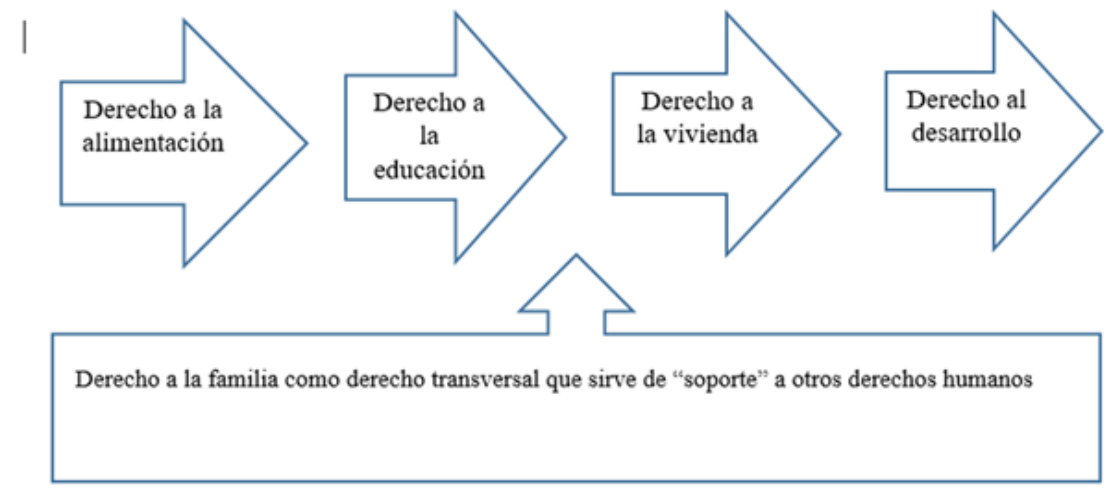

FIGURA 1

Derechos humanos que se potencian con base en el derecho humano a la familia

Fuente: elaboración propia

La conclusión de todo esto es que el derecho humano a la familia se traduce en la posibilidad real de hacer vivenciales los derechos de corte individual. Esto no significa que el derecho a la familia no tenga un disfrute personal y concreto. Desde luego que sí, pero también es cierto que para su adecuada configuración e incluso para su exposición más amplia y detallada, es menester esgrimir las especificidades de los demás derechos que se vuelven viables y atendibles, una vez que se articulan por el común denominador del derecho humano a la familia. Todo lo anterior nos lleva a plantear una nueva fórmula que pretende superar la fragilidad a que está expuesta la familia:

\section{Derecho humano a la familia + Garantias $=$ Derechos humanos plenos}

En nuestra concepción, este es el esquema que permitirá superar la vulnerabilidad de la familia y volver vivenciales y efectivos los derechos humanos de sus integrantes. Así, podemos decir que el derecho humano a la familia es un derecho de última generación que tiene su base en la necesidad de volver vivenciales otros derechos. Ergo, el derecho a la familia es el último desarrollo científico de los derechos humanos de carácter individual, que no tienen mejor escenario para su concreción que la familia.

Aun cuando los derechos humanos esenciales se materializan en su disfrute individual, pues no se les puede contextualizar de manera grupal o colectiva, el derecho a la familia es la expresión más refinada de un derecho que por sí mismo es capaz de servir como instrumento y vía para que otros derechos puedan ser vistos con posibilidades de acrecentamiento y aprehensión. De este modo, el derecho a la familia se convierte en un derecho humano de rango superior, pues además de constituir por sí mismo un atributo esencial de las personas, se le puede contextualizar como el derecho motor para la eficacia de otros derechos humanos. Desde luego, es necesario avanzar en la parte contextual que, sin duda, exigirá el reconocimiento formal del derecho humano a la familia en los ordenamientos constitucionales y legales e incluso de orden internacional. Sin embargo, el primer gran avance estará dado por su configuración científica y epistemológica.

Ahora bien, la pertenencia a este grupo humano debe mirarse desde la perspectiva de los derechos esenciales de cualquier persona que, por lo mismo, requieren ser afianzados para su adecuado disfrute. Esto significa que la necesidad humana de vivir al cobijo de un grupo familiar, se acompaña del correlativo derecho a vivir de este modo y a gozar de la protección que solo un grupo tan cercano puede prodigar. Líneas atrás citamos, a manera de ejemplo, el derecho a la alimentación y el derecho a la educación. A menos que pensemos en comedores comunitarios o en escuelas-dormitorio, los citados derechos no tienen otros escenarios para su disfrute fuera del núcleo familiar y, como ya señalamos, ni siquiera en estos supuestos podemos hablar de condiciones idóneas para ser vivenciados de manera óptima. Por tal razón, creemos que, así como estos, hay un gran elenco de derechos humanos, tanto de cariz individual como de corte grupal (pero finalmente de disfrute 
individual) que simplemente no pueden ser llevados al terreno de la vida cotidiana, si les falta el escenario, el contexto adecuado para su praxis.

Aquí reside lo que en nuestra concepción se puede asumir como la parte nuclear y más relevante del derecho humano a la familia; es decir, del derecho que todo individuo tiene a ser reconocido y tenido como sujeto del derecho grupal de disfrute individual a la vida en familia y a la consiguiente protección $y$ oportunidades de desarrollo que esta puede potenciar. Luego, entonces, el derecho en estudio se desdobla en dos grandes momentos: por una parte, se concreta en el reconocimiento de este derecho a todos los seres humanos; reconocimiento que por principio debe tener una dimensión constitucional y sus correspondientes concreciones en normas legales ordinarias y — de ser el caso- en tratados internacionales; en segundo lugar, al momento "vivencial" que se concreta en la praxis del mismo en el seno de un grupo cercano y afectivo que, sin duda, debe ser la familia.

\section{El estatus legislativo de la cuestión}

Como hemos dicho, las referencias de derecho positivo sobre el derecho a la familia son escuetas; ni qué decir sobre el derecho humano de la familia que sigue la misma tendencia poco precisa. Vamos a revisar cómo es tratada la cuestión en los ordenamientos internacionales y en la legislación mexicana, para conocer mejor esta situación de franca anomia. En este sentido, podemos adelantar una conclusión central, al afirmar que solamente la Declaración Universal de los Derechos Humanos - de manera tangencial- reconoce la existencia del derecho de la familia, aunque no con la fuerza que debiera manifestarlo, como se puede ver en el artículo 16.3 reproducido a continuación.

\section{Artículo 16}

1. Los hombres y las mujeres, a partir de la edad núbil, tienen derecho, sin restricción alguna por motivos de raza, nacionalidad o religión, a casarse y fundar una familia, y disfrutarán de iguales derechos en cuanto al matrimonio, durante el matrimonio y en caso de disolución del matrimonio.

...

3. La familia es el elemento natural y fundamental de la sociedad y tiene derecho a la protección de la sociedad y del Estado.

Como podemos ver, la familia como entidad "tiene derecho a ser protegida”; esto nos lleva a la focalización de su existencia como un ente distinto a sus integrantes. La familia —el grupo familiar - tiene así un reconocimiento tácito y en consecuencia, podemos afirmar la necesidad de su protección por parte del Estado. Por su parte, la Convención Americana sobre Derechos Humanos señala prácticamente lo mismo en el numeral 17.1:

Artículo 17. Protección a la Familia

1. La familia es el elemento natural y fundamental de la sociedad y debe ser protegida por la sociedad y el Estado.

2. Se reconoce el derecho del hombre y la mujer a contraer matrimonio y a fundar una familia si tienen la edad y las condiciones requeridas para ello por las leyes internas, en la medida en que estas no afecten al principio de no discriminación establecido en esta Convención.

De manera escueta, la Convención Sobre los Derechos del Niño se refiere a la familia en diversos apartados. Algunos son del tenor siguiente; por ejemplo, en el preámbulo refiere:

Convencidos de que la familia, como grupo fundamental de la sociedad y medio natural para el crecimiento y el bienestar de todos sus miembros, y en particular de los niños, debe recibir la protección y asistencia necesarias para poder asumir plenamente sus responsabilidades dentro de la comunidad.

En algunos artículos que citamos solo a manera de ejemplo, leemos: 
1. Ningún niño será objeto de injerencias arbitrarias o ilegales en su vida privada, su familia, su domicilio o su correspondencia, ni de ataques ilegales a su honra y a su reputación.

Artículo 27

2. A los padres u otras personas encargadas del niño les incumbe la responsabilidad primordial de proporcionar, dentro de sus posibilidades y medios económicos, las condiciones de vida que sean necesarias para el desarrollo del niño.

De la interpretación del contenido de estos dos preceptos, podemos colegir que la familia es el asiento natural para la vida y el desarrollo de los niños. Cuando el numeral 2 del artículo 27 señala: "A los padres u otras personas encargadas del niño..." consideramos que tal enunciado se refiere a la familia.

Con estas referencias del orden jurídico internacional, podemos aseverar que la familia tiene una existencia propia; como lógica consecuencia de esto, la familia debe ser protegida. Este es el estado de la cuestión: no hay una definición puntual sobre el derecho humano a la familia - si acaso la Convención sobre los Derechos del Niño lo señala de manera indirecta-, ni tampoco respecto a los medios de protección del derecho humano de la familia - apenas esbozado en forma declarativa-. Ahora bien, es pertinente señalar que se trata de un derecho humano de nuevo cuño ${ }^{18}$ y en evolución y, por ello, es comprensible la poco clara manifestación de los textos normativos y de los organismos internacionales sobre el particular. En la misma ruta se mantienen los Estados; en el caso concreto de México, la legislación prácticamente reproduce la misma concepción sobre este derecho, como podemos corroborar a continuación.

Dice así la Constitución Política de los Estados Unidos Mexicanos:

Artículo 4

$\cdots$

El varón y la mujer son iguales ante la ley. Esta protegerá la organización y el desarrollo de la familia.

Por su parte, la Ley General de los Derechos de Niñas, Niños y Adolescentes señala:

Artículo 13. Para efectos de la presente Ley son derechos de niñas, niños y adolescentes, de manera enunciativa más [sic] no limitativa, los siguientes:

$\cdots$

IV. Derecho a vivir en familia;

Artículo 22. Niñas, niños y adolescentes tienen derecho a vivir en familia. La falta de recursos no podrá considerarse motivo suficiente para separarlos de su familia de origen o de los familiares con los que convivan, ni causa para la pérdida de la patria potestad.

La Ley de Asistencia Social indica:

Artículo 5. La rectoría de la asistencia social pública y privada corresponde al Estado, el cual, en forma prioritaria, proporcionará servicios asistenciales encaminados al desarrollo integral de la familia, entendida como la célula de la sociedad que provee a sus miembros de los elementos que requieren en las diversas circunstancias de su desarrollo, y también a apoyar, en su formación y subsistencia, a individuos con carencias familiares esenciales no superables en forma autónoma.

El Estatuto Orgánico del Sistema Nacional para el Desarrollo Integral de la Familia señala:

Artículo 2. El Organismo, para el cumplimiento de sus objetivos y sin perjuicio de las establecidas en los ordenamientos jurídicos aplicables, contará con las siguientes atribuciones:

IV. Promover el desarrollo de la familia y de la comunidad...

De lo anteriormente transcrito, podemos concluir que el derecho humano a la familia está apenas aludido en la legislación mexicana y que, en estos ordenamientos referidos, como en otros similares que hay incluso en el ámbito de las entidades federativas, no advertimos una concepción adecuada sobre el contenido, alcances y posibilidades de este derecho esencial. 


\section{Proyección pragmática de su ejercicio}

Ahora bien, más allá de su reconocimiento formal, en este derecho tiene gran importancia lo que concierne a los medios más adecuados para su aseguramiento. En este punto, al referirnos a la garantía del citado derecho, enfocamos dos ámbitos concretos para su comprensión cabal: por un lado, la garantía como expresión primigenia de la tarea irrenunciable que compete al Estado para establecer el diseño óptimo encaminado al desarrollo y disfrute del derecho a la familia; por otra parte, la garantía en el sentido de medio de aseguramiento procesal constitucional para hacer viable el disfrute de este derecho.

Bien señala ROBERT ALEXY: "No solo la vida y la salud son bienes posibles de protección, sino todo aquello que, desde aspectos iusfundamentales, es digno de ser protegido, por ejemplo, la dignidad, la libertad, la familia y la propiedad" ${ }^{19}$. De este modo, la construcción de los dos escenarios arriba descritos requiere tanto de las políticas públicas diseñadas ex profeso para posibilitar la germinación del derecho en estudio, como del establecimiento de mecanismos procesales de naturaleza constitucional, viables y accesibles a los habitantes, para que estos puedan enderezar su exigencia por la vía procesal expedita y eficaz, a efecto de que el Estado genere las condiciones óptimas para que este derecho tenga posibilidades de apropiación y disfrute.

Por lo que se refiere a las políticas públicas, es fácil comprender la importancia de su estudio, diseño y adopción, para la mejor operación de la cosa pública ${ }^{20}$. En el caso que nos ocupa, este aspecto es esencial para asegurar el disfrute de los derechos humanos en el escenario de la familia. La implementación de las políticas públicas "es el cumplimiento de una decisión política básica" ${ }^{21}$. Aquí se ubica un momento trascendente en la actividad del Estado, pues indica claridad en el rumbo ${ }^{22}$, y nos parece que en este campo, la brújula apuesta por la prevención y todas las tareas profilácticas útiles en la generación de escenarios óptimos para que los derechos humanos en verdad florezcan. Vistas así, las políticas públicas son el entreveramiento entre el discurso y la acción. En esta tesitura, el derecho humano a la familia tiene una doble faceta; una proyección sustantivo-declarativa y, por otro lado, una proyección pragmático-adjetiva. La primera se configura a través de la conjunción de normas constitucionales y legales que recogen este derecho; la segunda se integra con las políticas públicas ${ }^{23}$ y con las herramientas procesales que ofrecen a los habitantes la posibilidad de exigir que sus derechos sean atendidos y asegurados por el Estado.

En el siguiente cuadro, damos cuenta de esta proyección dual que identifica los ordenamientos jurídicos y herramientas que reconocen y regulan el derecho a la familia. 
TABLA 1

La proyección dual del derecho a la familia

\begin{tabular}{|l|l|l|}
\hline Proyección & Aspecto instrumental & Prospectiva \\
\hline $\begin{array}{l}\text { Proyección sustantivo- } \\
\text { declarativa }\end{array}$ & $\begin{array}{l}\text { Constitución Política de los } \\
\text { Estados Unidos Mexicanos } \\
\text { Tratados internacionales } \\
\text { Leyes ordinarias }\end{array}$ & $\begin{array}{l}\text { Es necesaria la realización de } \\
\text { reformas constitucionales y } \\
\text { legales necesarias para el } \\
\text { reconocimiento expreso, claro } \\
\text { e indubitable de este derecho. }\end{array}$ \\
\hline $\begin{array}{l}\text { Proyección adjetivo- } \\
\text { pragmática }\end{array}$ & $\begin{array}{l}\text { Es necesario el diseño de } \\
\text { políticas públicas centradas en } \\
\text { la familia y la generación de } \\
\text { acciones de naturaleza } \\
\text { constitucional, a fin de } \\
\text { asegurar el disfrute de este } \\
\text { derecho. }\end{array}$ \\
& Mecanismos procesales & $\begin{array}{l}\text { Es pertinente la creación del } \\
\text { Proceso constitucional de } \\
\text { Habeas Familiae. }\end{array}$ \\
\hline
\end{tabular}

Fuente: elaboración propia

Como podemos advertir, es necesario dar mayor impulso a la dimensión prospectiva que mucho puede ayudar a mejorar el diseño y la atención a las proyecciones sustantivo-declarativa y adjetivo-pragmática. Lo antes señalado se visualiza mejor aún en el siguiente cuadro que de manera pormenorizada nos muestra qué tenemos y qué hace falta para introducir un rango deseable de eficacia al derecho humano a la familia. 
TABLA 2

Escenarios para la eficacia del derecho humano a la familia

\begin{tabular}{|c|c|c|}
\hline Escenarios & $\begin{array}{l}\text { Dimensión } \\
\text { Ex lege lata }\end{array}$ & $\begin{array}{l}\text { Dimensión } \\
\text { De lege ferenda }\end{array}$ \\
\hline $\begin{array}{l}\text { Constitución Política de los } \\
\text { Estados Unidos Mexicanos }\end{array}$ & $\begin{array}{l}\text { Texto escueto del artículo } 4 \text { de la } \\
\text { Constitución Política de los Estados } \\
\text { Unidos Mexicanos } \\
\text { Dice: } \\
\text { (Se deroga el párrafo primero) } \\
\text { E1 varón y la mujer son iguales ante la } \\
\text { ley. Esta protegerá la organización y el } \\
\text { desarrollo de la familia. } \\
\text {... } \\
\text { Toda familia tiene derecho a disfrutar } \\
\text { de vivienda digna y decorosa. La Ley } \\
\text { establecerá los instrumentos y apoyos } \\
\text { necesarios a fin de alcanzar tal } \\
\text { objetivo. }\end{array}$ & $\begin{array}{l}\text { Reforma al artículo } 4 \text { de la Constitución } \\
\text { Política de los Estados Unidos } \\
\text { Mexicanos } \\
\text { Debe decir: } \\
\text { (Se deroga el párrafo primero) } \\
\text { E1 varón y la mujer son iguales ante la } \\
\text { ley. } \\
\ldots \\
\text { Toda persona tiene derecho a la familia. } \\
\text { Toda familia tiene derecho a disfrutar, } \\
\text { como ente colectivo, de todos los } \\
\text { derechos humanos de sus integrantes. } \\
\text { Esta Constitución y las leyes } \\
\text { establecerán los instrumentos y apoyos } \\
\text { necesarios a fin de alcanzar tal objetivo. }\end{array}$ \\
\hline Tratados internacionales & $\begin{array}{l}\text { Solamente la Declaración Universal de } \\
\text { los Derechos Humanos reconoce el } \\
\text { Derecho a la familia }\end{array}$ & $\begin{array}{l}\text { Ampliar el reconocimiento de este } \\
\text { derecho en el ámbito internacional }\end{array}$ \\
\hline Leyes ordinarias & $\begin{array}{l}\text { Estatuto Orgánico del Sistema Nacional } \\
\text { para el Desarrollo Integral de la } \\
\text { Familia } \\
\text { Ley de Asistencia Social }\end{array}$ & $\begin{array}{l}\text { Amplia reforma legal que incluya y } \\
\text { atienda adecuadamente este derecho }\end{array}$ \\
\hline Políticas públicas & $\begin{array}{l}\text { Sistema DIF, SEDESOL, } \\
\text { CONEVAL }\end{array}$ & $\begin{array}{l}\text { Mayor claridad y concreción a los } \\
\text { Programas de Apoyo a la Familia }\end{array}$ \\
\hline Mecanismos procesales & Ninguno & $\begin{array}{l}\text { Sugerimos la implementación del } \\
\text { proceso constitucional que desde ahora } \\
\text { denominamos Habeas Familiae, } \\
\text { encaminado al aseguramiento de las } \\
\text { condiciones mínimas para el disfrute de } \\
\text { los derechos humanos en el seno } \\
\text { familiar. }\end{array}$ \\
\hline
\end{tabular}

Fuente: elaboración propia

El estado de la cuestión nos indica en la visión de lege ferenda, todo un catálogo de acciones insoslayables para que el derecho hasta aquí explorado, en verdad, pueda ser viable y defendible.

\section{A modo de conclusión}

Más allá de la nomenclatura o del discurso que se construye en torno a los derechos humanos de nuevo cuño, la concepción individual sigue marcando el derrotero en el tratamiento y evolución de este campo. Hemos dicho que, a fin de cuentas, el disfrute de cualquiera de estos derechos -incluso de los colectivos o difusosdesemboca en los individuos concretos. Pero esto no quiere decir que, a consecuencia del disfrute específico de cualquier derecho humano, todos y cualquiera de ellos de reciente creación deban seguir un proceso de configuración individual, clausurando con ello la posibilidad de otros desarrollos grupales o colectivos. 
Los nuevos derechos humanos o, mejor dicho, las nuevas orientaciones sobre los derechos humanos siguen la misma ruta prestablecida de corte individual. Por ello, el derecho (aun siendo incipiente que hemos abordado en el presente estudio, ha tenido idéntico tratamiento. En este sentido, si partimos de la relevancia que su concepción tiene para los seres humanos, es evidente que el derecho humano a la familia no ha tenido un desarrollo adecuado. En virtud de lo anterior, es necesario hacer un cambio en la forma de comprender y explicar los derechos humanos — más allá de la dimensión descriptiva de corte individual—, para dar paso a una nueva perspectiva teórica que sea capaz de expresar que hay algunos derechos humanos (como el de la familia que se explican mejor y se potencian aún más, si se les mira colectivamente.

Además de esto, la visión renovada del derecho humano a la familia se sitúa como un derecho humano con la capacidad para detonar el disfrute de otros más, $v \cdot g r$., el derecho a la alimentación, a la educación, a la vivienda ${ }^{25}$, etc. En este orden de ideas, el derecho humano a la familia, también requiere medios eficaces para su aseguramiento; id est, garantías que permitan al ente colectivo llamado familia, exigir el respeto y la protección que, desde ahora, le son debidas por la ley y el Estado.

Nos parece que con la siguiente pregunta concluimos el ciclo epistemológico propuesto: ‘acaso alguno de los derechos que hemos referido, como el derecho a la alimentación o a la educación, puede volverse viable fuera de la familia? Creemos que no. ¿Cuál de estos derechos se puede vivenciar fuera de la familia, siendo - como somos - vulnerables? En nuestra perspectiva, es imprescindible acompañar el derecho humano a la familia de sus correspondientes garantías. Una que hemos esbozado en el presente abordaje, la hemos denominado Habeas familiae que consistiría en una acción procesal constitucional para exigir el respeto y la protección del derecho a la familia; bien sabemos que una acción como la aquí planteada, debe ir acompañada de la planeación pertinente por parte del Estado, propicia para hacer eficaz y atendible este derecho; mediante la acción de Habeas familiae, cualquier persona podrá exigir al Estado que proteja esta institución clave que aquí hemos delineado como un derecho matriz y a la vez como un derecho motor, capaz de proyectar el desarrollo y disfrute de otros derechos también esenciales.

Ahora bien, la insuficiencia de políticas públicas, la fragilidad de la política y la ausencia del Estado en este campo generan claros vacíos que hacen poco viable el goce pleno de casi cualquier derecho. En el caso concreto que nos ocupa, la falta de garantías idóneas para el disfrute del derecho a la familia, materializada por la presencia de la vulnerabilidad, hace nugatoria la aprehensión de los derechos esenciales de los seres humanos. Por eso, resulta imprescindible que desde estos atisbos primigenios acerca de este derecho de nuevo cuño, las recientes proyecciones jurídicas sean capaces de advertir que más allá de la sola dimensión declarativa o hasta prescriptiva, el derecho humano a la familia debe contar con la adecuada envoltura protectora, tangible y procesalmente atendible, capaz de asegurar su vivencia cotidiana.

De aquí se desprende la exigencia de un cambio de perspectiva teórica que debe ser acompañada de acciones concretas en la adopción de políticas públicas y en la creación de mecanismos procesales constitucionales como el ya señalado-, capaces de garantizar el derecho humano a la familia y con ello, auspiciar el desarrollo de otros derechos humanos que no tienen mejor escenario que la familia. Si bien las aproximaciones vertidas en este trabajo todavía pueden contener imprecisiones, hemos tenido el propósito de generar una nueva vía para potenciar el disfrute de los derechos humanos; estamos convencidos de que la familia es el contexto insuperable para ello.

\section{Bibliografía}

\section{Libros}

AGUILAR-VILLANUEVA, LUIS F., El estudio de las politicas públicas (Miguel Ángel Porrúa, México, 2007. 
ALEXY, ROBERT, Teoria de los derechos fundamentales (Centro de Estudios Políticos y Constitucionales, CEPC, Madrid, 2002).

AZPIRI, JORGE, Uniones de hecho (Hammurabi, Buenos Aires, 2003).

BARTOLOMÉ-CENZANO, JOSÉ CARLOS DE, Derechos fundamentales y libertades públicas (Tirant lo Blanch, Valencia, 2003).

BIDART, GERMÁN, Casos de derechos humanos (Ediar, Buenos Aires, 1997).

BIDART, GERMÁN, Teoría general de los derechos humanos (Astrea, Buenos Aires, 1989).

COLAUTTI, CARLOS, Derechos humanos (Editorial Universidad, Buenos Aires, 1995).

FUGARETTA, JUAN CARLOS \& ROMANO, ESTHER, comps., Nuevas perspectivas interdisciplinarias en violencia familiar (Editorial Ad-Hoc, Buenos Aires, 2001).

GARDUÑO-ESTRADA, LEÓN; SALINAS-AMESCUA, BERTHA \& ROJAS-HERRERA, MARIANO, coords., Calidad de vida y bienestar subjetivo en México (Universidad de las Américas, Centro de Estudios sobre Calidad de Vida y Desarrollo Social, International Society of Quality of Life Studies, Plaza y Valdés, México, 2005).

GROSMAN, CECILIA P. \& MARTÍNEZ-ALCORTA, IRENE, Familias ensambladas, nuevas uniones después del divorcio (Editorial Universidad, Buenos Aires, 2000).

HUMBOLDT, WILHELM VON, Los limites de la acción del Estado (Tecnos, Madrid, 2009).

LAMBERTI, SILVIO; SÁNCHEZ, AURORA \& VIAR, JUAN P., comps., Violencia familiar y abuso sexual (Editorial Universidad, Buenos Aires, 2003).

MEDINA, GRACIELA, Uniones de hecho. Homosexuales (Rubinzal-Culzoni Editores, Buenos Aires, 2001).

MOTA-DÍAZ, LAURA \& CATTANI, ANTONIO DAVID, coords., Desigualdad, pobreza, exclusión y vulnerabilidad en América Latina. Nuevas perspectivas analiticas (Universidad Autónoma del Estado de México, UAEMex, Centro de Estudios Sobre Marginación y Pobreza del Estado de México, Universidade Federal do Rio Grande do Sul, UFRGS, Asociación Latinoamericana de Sociología, ALAS, México, 2004).

NINO, CARLOS SANTIAGO, Ética y derechos humanos, un ensayo de fundamentación (Astrea, Buenos Aires, 1989).

OSBORNE, DAVIS \& GAEBLER, TED, La reinvención del gobierno, la influencia del espiritu empresarial en el sector público (Paidós, Barcelona, 1994).

MOSSET, JORGE, El valor de la vida humana (Rubinzal-Culzoni, Buenos Aires, 2002).

SABATIER, PAUL \& MAZMANIAN, DANIEL, La implementación de la politica pública: un marco de análisis, en La implementación de las politicas, 323-372 (LUIS F. AGUILAR-VILLANUEVA, coord., Miguel Ángel Porrúa, México, 2007

STILERMAN, MARTA \& SEPLIARSKY, SILVIA, Adopción, integración familiar (Editorial Universidad, Buenos Aires, 1999)

URIBE-ARZATE, ENRIQUE, La naturaleza constitucional dual del derecho a la información y su papel en la construcción del Estado constitucional en México (Instituto de Transparencia y Acceso a la Información Pública del Estado de México y Municipios, INFOEM, México, 2010).

\section{Revistas}

ACEVEDO-QUIROZ, LUIS HERNANDO, El concepto de familia hoy, LIII Franciscanum, Revista de las Ciencias del Espiritu, 149-170 (2011). Disponible en: http://www.redalyc.org/articulo.oa?id=343529077006

Conceptos básicos para el estudio de las familias, 7 Archivos en Medicina Familiar, 1, 15-19 (2005). Disponible en: http://www.redalyc.org/articulo.oa?id=50712789003, http://www.medigraphic.com/cgi-bin/new/contenido .cgi? IDPUBLICACION=660

FINEMAN, MARTHA ALBERTSON, The Vulnerable Subject: Anchoring Equality in the Human Condition, 20 Yale Journal of Law \& Feminism, 1, 1-23 (2008). Disponible en: https://digitalcommons.law.yale.edu/cgi/vie wcontent.cgi?article $=1277 \&$ context $=y j l f$ 
MACHADO-JIMÉNEZ, JOSÉ ALEJANDRO, La transformación del concepto constitucional de familia. Alcances de una problemática teórica, 23 Dikaion, 1 (2014). DOI: 10.5294/dika.2014.23.1.5. Disponible en: http://dik aion.unisabana.edu.co/index.php/dikaion/article/view/3093/3614

PISARELLO, GERARDO, Del Estado social legislativo al Estado social constitucional: por una protección compleja de los derechos sociales, 15 Isonomia: Revista de Teoria y Filosofía del Derecho, 81-107 (2001). Disponible en: h ttp://www.scielo.org.mx/pdf/is/n15/1405-0218-is-15-00081.pdf

PROAG, VIRENDRA, The Concept of Vulnerability and Resilience, 18 Procedia Economics and Finance, 369-376 (2014). DOI: 10.1016/S2212-5671(14)00952-6. Disponible en: https://ac.els-cdn.com/S2212567114009526/1-s2.0-S2212567114009526-main.pdf?_tid=76427665-a05 0-4d61-8eb0-9e4639f278c68acdnat=1535050040_5f9291b5b48af24ab65daa2ceb44011a

ROSSI, STEFANO, La famiglia di fatto nella giurisprudenza della Corte Costituzionale, 4 Forum di Quaderni Costituzionali Rassegna, 135-172 (2007). Disponible en: http://www.forumcostituzionale.it/wordpress/?p=40 85, http://www.forumcostituzionale.it/wordpress/images/stories/pdf/nuovi\%20pdf/Paper/0029_rossi.pdf

URIBE-ARZATE, ENRIQUE, Una aproximación a los derechos humanos desde la dimensión vivencial pragmática, XLIV Boletin Mexicano de Derecho Comparado, 132, 1233-1257 (2011). Disponible en: http://www.scielo.org .mx/pdf/bmdc/v44n132/v44n132a7.pdf

URIBE-ARZATE, ENRIQUE \& ROMERO-SÁNCHEZ, JESÚS, Vulnerabilidad y victimización en el Estado mexicano, XIV Espiral, 42, 75-95 (2008). Disponible en: https://www.redalyc.org/articulo.oa?id=13804203

\section{Normativa mexicana}

Estados Unidos Mexicanos, Constitución Política, Diario Oficial de la Federación, 5 de febrero de 1917. Disponible en: https://www.scjn.gob.mx/constitucion-politica-de-los-estados-unidos-mexicanos

Estados Unidos Mexicanos, Estatuto Orgánico del Sistema Nacional para el Desarrollo Integral de la Familia, Diario Oficial de la Federación, 11 de mayo de 2016. Disponible en: http://www.diputados.gob.mx/LeyesBiblio/regla /n252.pdf

Estados Unidos Mexicanos, Ley de Asistencia Social, Diario Oficial de la Federación, 2 de septiembre de 2004. Disponible en: http://www.diputados.gob.mx/LeyesBiblio/pdf/270_240418.pdf

\section{Tratados internacionales}

Organización de Estados Americanos, OEA, Convención Americana sobre Derechos Humanos, San José, Costa Rica, 7-22 de noviembre de 1969. Disponible en: https://www.oas.org/dil/esp/tratados_b-32_convencion_america na_sobre_derechos_humanos.htm

Organización de Naciones Unidas, ONU, Convención sobre los Derechos del Niño, adoptada y abierta a la firma y ratificación por la Asamblea General en su Resolución 44/25, de 20 de noviembre de 1989. Disponible en: htt p://www.un.org/es/events/childrenday/pdf/derechos.pdf

Organización de Naciones Unidas, ONU, Declaración Universal de los Derechos Humanos, proclamada por la Asamblea General de las Naciones Unidas en su Resolución 217 A (III), París, 10 de diciembre de 1948. Disponible en: http://www.un.org/es/universal-declaration-human-rights/

\section{Direcciones web}

http://www.unicef.org/mexico/spanish/17046.htm 
Notas

1 Vale referir que múltiples estudios realizados desde diferentes enfoques dan cuenta de esta cuestión. Cfr. MARTA STILERMAN \& SILVIA SEPLIARSKY, Adopción, integración familiar (Editorial Universidad, Buenos Aires, 1999). GRACIELA MEDINA, Uniones de hecho. Homosexuales (Rubinzal-Culzoni Editores, Buenos Aires, 2001). JORGE AZPIRI, Uniones de hecho (Hammurabi, Buenos Aires, 2003). SILVIO LAMBERTI, AURORA SÁNCHEZ \& JUAN P. VIAR, comps., Violencia familiar y abuso sexual (Editorial Universidad, Buenos Aires, 2003). JUAN CARLOS FUGARETTA \& ESTHER ROMANO, comps., Nuevas perspectivas interdisciplinarias en violencia familiar (Editorial Ad-Hoc, Buenos Aires, 2001).

2 LUIS HERNANDO ACEVEDO-QUIROZ, El concepto de familia hoy, LIII Franciscanum, Revista de las Ciencias del Espiritu, 149-170, 156, 169 (2011).

3 Conceptos básicos para el estudio de las familias, 7 Archivos en Medicina Familiar, 1, 15-19 (2005).

4 CECILIA P. GROSMAN \& IRENE MARTÍNEZ-ALCORTA, Familias ensambladas, nuevas uniones después del divorcio, 32 (Editorial Universidad, Buenos Aires, 2000).

$5 \mathrm{Al}$ respecto, podemos destacar un interesante estudio sobre una decisión de la Corte Constitucional colombiana que ha tratado la cuestión. Ahí, se destaca que: Aun habiendo sido reconocida por esta corporación en sus anteriores sentencias con carácter de jurisprudencia vinculante, el que la pareja que da inicio a la familia se estructura a partir de la monogamia y la heterosexualidad, la Corte Constitucional colombiana reformó el artículo 42 de la Constitución Política e impuso, por un ejercicio formalístico de sus poderes, la doctrina ideológica de que las relaciones homosexuales se deben tomar como actos que producen vínculos que caracterizan legalmente a las familias en Colombia, JOSÉ ALEJANDRO MACHADO-JIMÉNEZ, La transformación del concepto constitucional de familia. Alcances de una problemática teórica, 23 Dikaion, 1 (2014). DOI: 10.5294/dika.2014.23.1.5

6 Para mayor referencia sobre la familia y sus tipos: STEFANO ROSSI, La famiglia di fatto nella giurisprudenza della Corte Costituzionale, 4 Forum di Quaderni Costituzionali Rassegna, 135-172 (2007).

7 "The concept of vulnerability implies some risk combined with the level of social and economic liability, and the ability to cope with the resulting event. Vulnerability has been defined as the degree to which a system, or part of a system, may react adversely during the occurrence of a hazardous event". VIRENDRA PROAG, The Concept of Vulnerability and Resilience, 18 Procedia Economics and Finance, 369-376, 370 (2014). DOI: 10.1016/S2212-5671(14)00952-6

8 MARTHA ALBERTSON FINEMAN, The Vulnerable Subject: Anchoring Equality in the Human Condition, 20 Yale Journal of Law \& Feminism, 1, 1-23, 9 (2008).

9 Sin duda, este es el derecho humano "mayor"; se trata del derecho humano "más fundamental" que tiene que ser acompañado del disfrute pleno de otros derechos. "De donde con la expresión derecho a la vida no solo se señala el interés jurídicamente protegido a seguir viviendo, a que no se anticipe el deceso de la persona viva, sino también el derecho subjetivo a que se mantenga la vida en su plenitud, a que no se la limite o cercene". JORGE MOSSET, El valor de la vida humana, 66 (Rubinzal-Culzoni, Buenos Aires, 2002). A mayor abundamiento, puede verse el excelente trabajo de CARLOS SANTIAGO NINO, Ética y derechos humanos, un ensayo de fundamentación (Astrea, Buenos Aires, 1989), en particular los capítulos V y VI que tratan de la autonomía y de la inviolabilidad de la persona, respectivamente. No parece que estos dos conceptos centrales fortalezcan la idea de procurar para las personas, umbrales mayores de certidumbre y bienestar que eviten y, de ser posible, erradiquen, la vulnerabilidad.

10 ENRIQUE URIBE-ARZATE \& JESÚS ROMERO-SÁNCHEZ, Vulnerabilidad y victimización en el Estado mexicano, XIV Espiral, 42, 75-95 (2008).

11 Los grandes problemas de ausencia de políticas públicas y, en general, de falta de intervención del Estado en la atención y cuidado de los derechos de las personas son lato sensu, causa primordial de la violación constante de los derechos esenciales. Cfr. LEÓN GARDUÑO-ESTRADA, BERTHA SALINAS-AMESCUA \& MARIANO ROJAS-HERRERA, coords., Calidad de vida y bienestar subjetivo en México (Universidad de las Américas, Centro de Estudios sobre Calidad de Vida y Desarrollo Social, International Society of Quality of Life Studies, Plaza y Valdés, México, 2005). LAURA MOTA-DÍAZ \& ANTONIO DAVID CATTANI, coords., Desigualdad, pobreza, exclusión y vulnerabilidad en América Latina. Nuevas perspectivas analiticas (Universidad Autónoma del Estado de México, UAEMex, Centro de Estudios Sobre Marginación y Pobreza del Estado de México, Universidade Federal do Rio Grande do Sul, UFRGS, Asociación Latinoamericana de Sociología, ALAS, México, 2004).

12 ENRIQUE URIBE-ARZATE \& JESÚS ROMERO-SÁNCHEZ, Vulnerabilidad y victimización en el Estado mexicano... (2008).

13 La idea de que el Estado debe dar seguridad y respetar a los ciudadanos la libertad para decidir, fue planteada con acierto por WILHELM VON HUMBOLDT, quien afirmó: "Para mí, el supremo ideal en la coexistencia de los seres humanos sería aquel en que cada uno se desarrollase solamente desde sí mismo y en virtud de sí mismo”. WILHELM VON HUMBOLDT, Los límites de la acción del Estado, 18 (Tecnos, Madrid, 2009). 
14 "Precisamente, con el objeto de remover la frecuente impunidad en la vulneración de las obligaciones estatales primarias por parte de las mayorías políticas coyunturales, las Constituciones modernas suelen contemplar una serie garantías constitucionales secundarias, jurisdiccionales e incluso semi-jurisdiccionales (Defensores del Pueblo, Comisiones de Derechos Humanos), dirigidas a resolver las antinomias y a colmar las lagunas jurídicas producidas como consecuencia de la violación de las garantías legislativas primarias" (itálicas en el original). GERARDO PISARELLO, Del Estado social legislativo al Estado social constitucional: por una protección compleja de los derechos sociales, 15 Isonomía: Revista de Teoría y Filosofía del Derecho, 81-107, 97 (2001).

15 Sobre el particular, ENRIQUE URIBE-ARZATE, Una aproximación a los derechos humanos desde la dimensión vivencial pragmática, XLIV Boletín Mexicano de Derecho Comparado, 132, 1233-1257 (2011). El autor afirma que los derechos sin garantías son derechos de papel; por tanto, es necesario que cuenten con la posibilidad real de su vivencia y disfrute y, asimismo, con los mecanismos para su protección y salvaguarda. Esta perspectiva se vincula con lo que BIDART llama los derechos a los que "hay que acceder", a diferencia de los derechos en que "se está". GERMÁN BIDART, Teoría general de los derechos humanos, capítulo primero, parágrafo 6, 22-23 (Astrea, Buenos Aires, 1989).

16 A manera de ejemplo, ENRIQUE URIBE-ARZATE, La naturaleza constitucional dual del derecho a la información y su papel en la construcción del Estado constitucional en México (Instituto de Transparencia y Acceso a la Información Pública del Estado de México y Municipios, INFOEM, México, 2010). Este autor explica por qué el derecho a la información puede ser entendido como un derecho configuración, justamente porque potencia la posibilidad de ejercer otros derechos, v. gr., el derecho de petición.

17 JOSÉ CARLOS DE BARTOLOMÉ-CENZANO, Derechos fundamentales y libertades públicas, 137 (Tirant lo Blanch, Valencia, 2003).

18 Cfr. CARLOS COLAUTTI, CARLOS COLAUTTI, Derechos humanos (Editorial Universidad, Buenos Aires, 1995), especialmente el capítulo XVII, Protección del matrimonio y la familia.

19 ROBERT ALEXY, Teoría de los derechos fundamentales, 436 (Centro de Estudios Políticos y Constitucionales, CEPC, Madrid, 2002).

20 LUIS F. AGUILAR-VILLANUEVA, El estudio de las políticas públicas (Miguel Ángel Porrúa, México, 2007).

21 PAUL SABATIER \& DANIEL MAZMANIAN, La implementación de la política pública: un marco de análisis, en La implementación de las políticas, 323-372, 329 (LUIS F. AGUILAR-VILLANUEVA, coord., Miguel Ángel Porrúa, México, 2007).

22 A modo de ejemplo, citamos lo siguiente: "Hubo un tiempo en el que nuestros gobiernos se concentraron más en la prevención; en construir servicios de aguas y sistemas de alcantarillado, para prevenir la enfermedad; en mejorar las normativas de los edificios para prevenir los incendios; en inspeccionar la leche, la carne, los restaurantes, para prevenir las enfermedades; en investigación que lograba vacunas y otras soluciones médicas, para eliminar las enfermedades. Pero a medida que desarrollaron más capacidad para proporcionar servicios, sus atenciones cambiaron. A medida que se profesionalizaron los departamentos de bomberos, desarrollaron el arte de apagar el fuego, no de prevenirlo. A medida que se profesionalizaron los departamentos de policía, se concentraron en atrapar a los delincuentes, no en ayudar a las comunidades en la prevención de los delitos”. DAVIS OSBORNE \& TED GAEBLER, La reinvención del gobierno, la influencia del espiritu empresarial en el sector público, 307-308 (Paidós, Barcelona, 1994).

23 "Colocar la supervivencia infantil en el primer plano del contexto crisis en la agenda pública ha revertido en la consecución de una mayor transferencia de presupuesto a programas como Oportunidades, que este año [2018] beneficia a un millón más de familias que se suman a los dos millones y medio que ya eran beneficiarias en 2009. Por primera vez se apoya a familias con niños y niñas de cero a nueve años. Oportunidades se ha convertido en el mayor programa mexicano de apoyo económico a las familias y una experiencia líder a nivel mundial en protección social. UNICEF establece sinergias con este programa a través de su trabajo en políticas públicas, especialmente en los estados de Oaxaca y Zacatecas". Disponible en: http://www.unicef.org/mexico/spanish/17046.htm

24 Sistema Nacional para el Desarrollo Integral de la Familia, DIF; Secretaría de Desarrollo Social [hoy Secretaría de Bienestar] SEDESOL; Consejo Nacional de Evaluación de la Política de Desarrollo Social, CONEVAL.

25 A manera de ejemplo, el caso propuesto por BIDART en el que una pareja no casada que tiene dos hijos, se inscribe en un Plan de Vivienda Familiar, pero les niegan el acceso a la vivienda por no estar casados. El alegato central de los actores es “...que los cinco años de vida en común son suficientes para probar la estabilidad de su unión de hecho y que casarse o no es una decisión que les incumbe de modo privativo e íntimo. Añaden que \#familia\# no es únicamente la que surge de las nupcias, y que \#vivienda familiar\# debe interpretarse, en consecuencia, como aquella destinada a un grupo familiar, con independencia de su origen". GERMÁN BIDART, Casos de derechos humanos, 315-316 (Ediar, Buenos Aires, 1997). Con este ejemplo queda clara la capacidad del derecho a la familia como un derecho motor que puede potenciar el disfrute de otros derechos.

* Artículo de investigación.

Licencia Creative Commons CC BY 4.0 
* Artículo de investigación.

Licencia Creative Commons CC BY 4.0

Para citar este articulo / To cite this article: URIBE-ARZATE, ENRIQUE \& BUSTAMANTEMEDRANO, MARTHA GUADALUPE, Notas sobre el derecho bumano a la familia como derecho motor para el ejercicio de otros derechos humanos, 138 Vniversitas (2019. https://doi.org/10.11144/Javeriana.vj1 38.ndhf 